\title{
DESIGN OPTIMIZATION OF PIPING ARRANGEMENTS IN SERIES SHIPS BASED ON THE MODULARIZATION CONCEPT
}

\author{
Gunawan $^{1 *}$, Kunihiro Hamada ${ }^{1}$, Takuo Deguchi ${ }^{1}$, Hiroyuki Yamamoto ${ }^{2}$, Yasufumi Morita ${ }^{2}$ \\ ${ }^{1}$ Graduate School of Engineering, Hiroshima University, 1-4-1 Kagamiyama, Higashi-Hiroshima \\ City, Hiroshima, Japan, 739-8527 \\ ${ }^{2}$ Tsuneishi Shipbuilding Co., Ltd., 1083, Tsuneishi, Numakuma-cho, Fukuyama City, Hiroshima, \\ Japan, 720-0393
}

(Received: December 2017 / Revised: January 2018 / Accepted: May 2018)

\begin{abstract}
The shipbuilding industry is currently operating in a state of intense market competition. In order to compete in the global market, shipbuilders must produce ships that are more efficient and which can be constructed in a relatively short turnaround time between order placement and delivery. This necessitates the development of new methods such as the building of series of ships, design optimization, and the modularization concept. This paper presents a design optimization approach based on the modularization concept for engine room design. The proposed method focuses on the following characteristics: piping systems, employed in multiple bulk carrier-series ships, of different sizes. Consideration is given to the cost and weight of these systems and the similarity and common features of the modules and arrangements concerned. The piping system design process is divided into two stages - module definition and arrangement design. A design structure matrix is adopted to define an effective module that could be employed for use in the design of various series of ships. An optimization system has been developed for use in the arrangement design stage. It uses a genetic algorithm to obtain a similar pattern for module arrangement in various series of ships, with specific consideration extended to cost and similarity. The details of the proposed method are discussed in this paper. In addition, the paper discusses the piping system design of an actual ship by using the proposed method and evaluates its effectiveness.
\end{abstract}

Keywords: Arrangement; Design optimization; DSM; Modularization; Piping system

\section{INTRODUCTION}

Provide In the shipbuilding industry, production methods are continuously being improved in a bid to achieve greater values of design efficiency. Production concepts such as block division, modularization, and shipbuilding to a standard design potentially offer solutions to the need to improve production capability. Typically, the initial design of an engine room may be based on advanced design data such as ship reference data, design constraints, and theoretical optimum solutions. The design of an engine room, including the piping system, is a complex process. Thus, the modularization of its design is an effective strategy for minimizing the complexity of the system. In applications such as shipbuilding, individual designs for engine room piping systems, along with their specifications and arrangements, differ significantly from one ship to another owing to differences in ship sizes.

\footnotetext{
*Corresponding author's email: d155784@hiroshima-u.ac.jp, Tel.+81-90-80613576, Fax.+81-82-4227194 Permalink/DOI: https://doi.org/10.14716/ijtech.v9i4.969
} 
Considering the above-mentioned characteristics of piping system design in shipbuilding applications, it is important for shipbuilders to develop a method based on standard modularization while also considering the different sizes of the vessels in a series of ships. In addition, the development of a standard modular arrangement is important in terms of achieving overall design optimization. Jaquith et al. (1996) were the first to introduce the concept of modularization for use in engine room design and its arrangement. They proposed a concurrent engineering system to simplify the construction of outfitting and equipment used in the engine room.

The view regarding modularization is gradually changing, and nowadays, the modularization concept is being employed in relation to the overall optimization of vehicles in the automobile industry. Consider the example of Nissan Motors' Common Module Family, which is a modular architecture concept that can be applied to a variety of different vehicles. As such, it enables the efficient design and manufacture of models such as small cars, sedans, and SUVs, simply by altering the combination of engine compartment, cockpit, and front and rear underbodies as modular units. The adoption of this type of approach to modularization provides an opportunity to enhance the design of engine rooms in shipbuilding.

This study proposes an engine room design methodology based on the modularization concept described above that could be employed in the design and manufacture of various series. Furthermore, the study proposes a modular arrangement inside the engine room optimized through the use of a genetic algorithm, taking the operating cost and similarity of arrangements as its objective functions.

As previously discussed, modularization and parts arrangement with regard to piping design are important considerations when seeking to realize the overall optimization of engine room design in a series of ships. As such, a number of prior studies have sought to examine these aspects.

Baade et al. (1998) explored the modularization concept based on the grouping of system components inside an engine room. Further, they proposed the concept of engine room modularization in the form of a modular standard container based on functional volume. As a result, the engine room was divided into 13 individual units or modules. Tomassoni et al. (2003) proposed a novel modularization methodology comprising an advanced design methodology of grouping the equipment into a functional volume and a block, with an interface considered between the two.

In 2009, automatic modularization of the engine room was introduced by Koga et al. (2009). They used the design structure matrix (DSM) technique to generate a modular division of the engine room of a ship using a modular division algorithm, with the results being evaluated using functional completeness and module independence. Regarding the arrangement of an engine room, a number of researchers (Wu et al., 1998; Helvacioglu \& Insel, 2005; Singh \& Sharma, 2006; Kim et al., 2009; Kimura, 2011; Lee et al., 2013) have employed different algorithms and sequential coordination to optimize machinery arrangement and pipe routing. Their studies have tended to focus on the optimization of engine room arrangement, plant-equipment layout, and pipe routes. However, none of the studies have looked at the modularization of engine room equipment. The optimization using genetic algorithm in other field is reported by Chen et al. (2011). He conducted genetic algorithm to optimize the crew assignment for construction project planning.

In addition, the prior studies have focused only on the modularization and parts arrangement of either a single ship or of several individual components. Series of ships, in particular, have not been considered in any of the previous studies. Therefore, this study discusses a new modularization concept and arrangement and has the following characteristics: the target ships 
are various types of series ships; module commonality among all ships is considered, and the similarity in the arrangement of the modules for all ships is considered. The proposed concept is used in an actual ship design process and its effectiveness is evaluated.

\section{METHODS}

\subsection{Problem Definition}

\subsubsection{Target ships}

The details of the target ships, the design of which is considered in the proposed research, are listed as follows.

- Multiple series of bulk carriers with different capacities are considered. The respective sizes of the series considered herein are Handymax (58000 DWT), Panamax (82000 DWT), and over Panamax (98000 DWT). A single series comprises a significant number of ships.

- The piping system within the engine room of each ship comprises a fuel system, lubricating oil system, seawater system, freshwater system, compressed air system, and steam system.

- Each ship also features different components and arrangements within its piping system based on the requirements of the owner. Moreover, the sizes of the components depend on the overall size of the bulk carriers.

\subsubsection{Basic concept}

The primary objective of this study is to develop a methodology for arranging the parts of an engine room using the modularization concept, with due consideration being given to the various types of series ships. To fulfill this objective, arrangement of the parts is divided into the following two problems.

\subsubsection{The module definition problem}

Modularization involves the grouping of parts with strong dependency into a single group. The modularization of the common parts should be separate from that of the optional parts. The output of this process is in the form of a common module for ships belonging to various series types and an optional module that can be used for any particular ship. The modularization requirements are as follows.

- Modules should be defined for a single ship, a single series of ships, or for multiple series of ships.

- Based on an owner's requirements, both the common and optional modules should be sufficiently flexible to changes in capacity and size with no need for a change in module configuration.

- It should be possible to use a combination of common and optional modules to obtain a new ship type based on the owner requirements.

- To effectively utilize the modularization concept, complex connections should be included in the module. Therefore, the total number of connections between the individual modules should be minimized.

\subsubsection{Module arrangement problem}

Following the module definition process, the defined modules are arranged inside the engine room in a process termed the module arrangement problem. The following aspects are considered in this step.

- Constraints such as the space requirements for maintenance and area for fixed components.

- The similarity of arrangements for either a single ship, a series of ships, or multiple series of ships. Pipe costs are minimized with respect to pipe length, diameter, material, etc.

\subsection{Details of Modularization}

The module definition problem is addressed in the following five steps. The details of each step are discussed herein. 


\subsubsection{Piping diagram (user input)}

A piping diagram for all systems and all series of ships is required to define the individual modules. In this study, the fuel system, lubricating oil system, seawater system, freshwater system, compressed air system, and steam system are considered to make up the piping system.

\subsubsection{E-R model for each ship}

To establish the relationships between the various parts, the proposed study employs the entityrelationship model (or E-R model), which graphically represents the logical relationships between the different entities (objects). This model was first proposed by Peter Pin-Shan Chen of the Massachusetts Institute of Technology in the 1970s (Chen, 1976). In E-R modeling, the objects are represented via an entity, its relationship, and attributes, all of which may be defined as follows.

- An entity may have either a physical or logical existence. The proposed study identifies equipment such as the cooler, heater, purifier, filter, etc., as entities.

- Relationships denote the manner in which the entities are related to one another. In this study, the pipes connecting the individual entities are identified as relationships.

- Attributes basically refers to the properties of the entities. In this case, the flow capacity, heating value, part size, pipe diameter, etc. are considered as attributes.

Figure 1a depicts the E-R model of a simple piping system for Ship 1. The entities are the pump, cooler, generator, and heater. The attributes of each entity in Ship 1, as depicted in the figure, include pump capacity $\left(500 \mathrm{~m}^{3}\right)$, cooler capacity $\left(500 \mathrm{~m}^{3}\right)$, generator power $(500 \mathrm{~kW})$, heater heating value $(9000 \mathrm{~kJ})$, and pipe diameter $(125 \mathrm{~mm})$. As mentioned earlier, the relationship between the individual entities is represented via the corresponding pipe connections. The straight lines in the figure represent the pipes connecting the individual entities.

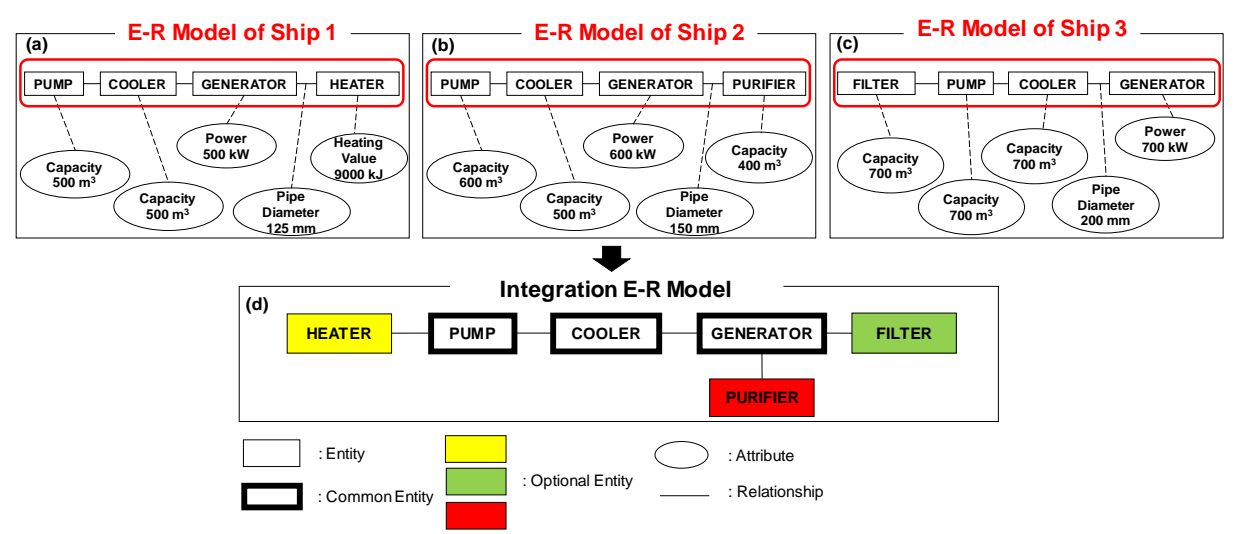

Figure $1 \mathrm{E}-\mathrm{R}$ model and its integration

\subsubsection{E-R model for multiple series of ships}

Following the generation of the E-R model for each ship, individual E-R models were integrated into a single model with a specific focus on the entities and their relationships. Figure 1d depicts an example of such integration. The entities in this case are estimated to be similar; therefore, similar entities and relationships can be integrated into a single entity or relationship. Thereafter, the entities and relationships are classified into the following two types.

- Common entities and relationships: These entities and relationships are employed in all types of ships. In this case, the pump, cooler, and generator qualify as common entities.

- Optional entities and relationships: These entities and relationships are used in only a few of the ships - a certain series of ships, or ships constructed for certain owners. 


\subsubsection{Modularization using DSM}

DSM is a network modeling tool used to represent the elements in a system and their interactions. It enables the user to model, visualize, and analyze the dependencies among different entities of any system and derive suggestions for the improvement or synthesis of a system (Kamrani \& Salhieh, 2002; Lindemann et al., 2009; Eppinger \& Browning, 2012). Figure 2 depicts the typical flow of a DSM process. Figure 2a depicts an E-R model comprising 7 entities and 12 relationships, wherein the relationships were set using weights. In this case, the two types of weight relationships are represented via the numbers 2 and 10 - a straight line for 2 and a dashed line for 10. It should be noted here that a higher number represents a stronger relationship. Once the weights were assigned, the weighted relationships were represented via a matrix (Figure $2 \mathrm{~b}$ ). A clustering algorithm was used to generate the clusters by re-ordering the entity list to obtain filled shells near the diagonal. In Figure 2c, the clusters (modules) are represented via black boxes. The results of the clustering operation help in defining the modules, as depicted in Figure $2 \mathrm{~d}$. The flow path of the DSM procedure followed in this study is illustrated in Figure 3.
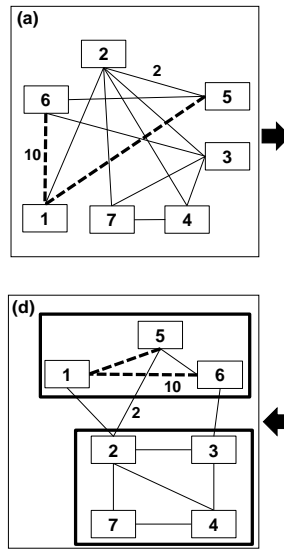

Figure 2 Flow path of the DSM
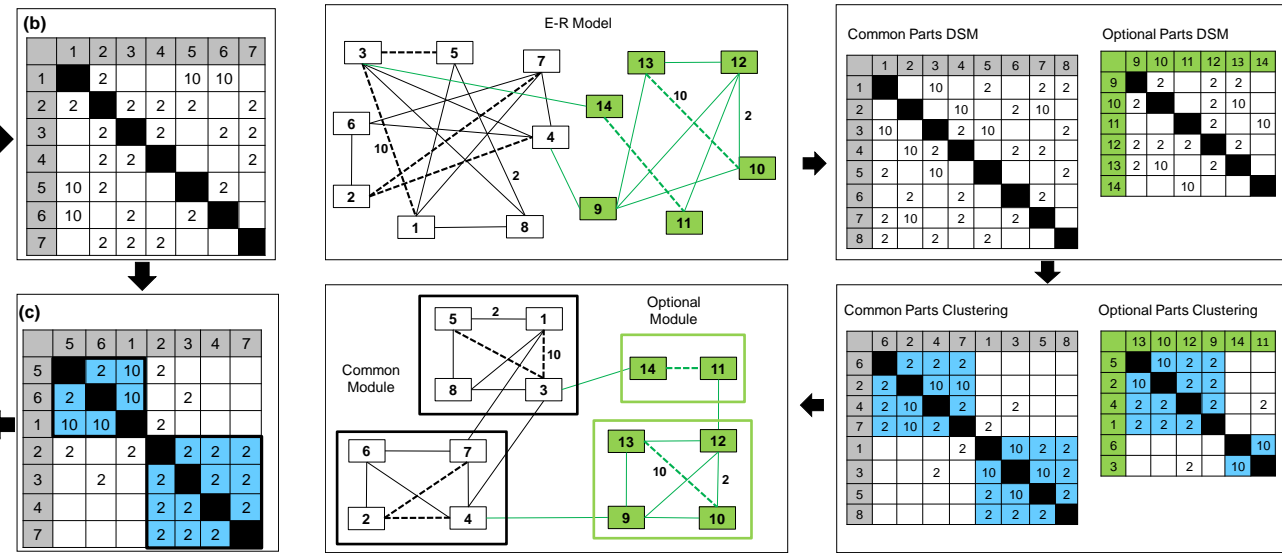

Figure 3 DSM procedure employed in this study

\subsubsection{Modularization result}

In the proposed study, each ship comprises six piping systems. Consider the example of a seawater system; it comprises 233 common and 8 optional components. This type of modularization is realized for a single ship or a series of ships, and also for ships belonging to various series types that could be established with 15 common and 2 optional modules. Each module can be varied in capacity or size with no change to its configuration. Therefore, it was possible to configure a new piping system combining all modules. The arrangement comprises 40 pipe connections between the grouped modules and 233 pipe connections within the modules. Therefore, the proposed method satisfies all of the requirements listed in section 2.1.2.1.

\subsection{Details of Arrangement Design}

\subsubsection{Basic concept}

In arrangement design, the modules defined in the previous section are arranged inside the engine room. To realize an arrangement for multiple series ships, the following concepts were introduced in this study.

- The arrangements of three series ships were executed simultaneously. This provides the flexibility to consider various options at once.

- In the aforementioned case, the design space becomes relatively large; moreover, it is difficult to obtain an optimum solution in a limited time when the positions of the modules are directly considered as design valuables. Therefore, the decks within the engine room and individual modules were divided into meshes. 
- The cost of the pipes and the similarity of the arrangements were set as objective functions. Furthermore, a genetic algorithm was adopted for optimization.

\subsubsection{Initial condition (user input)}

Deck, module, and inter-module pipe information was the input provided by the user prior to the commencement of optimization. This was considered as the initial condition for the arrangement optimization algorithm.

\subsubsection{Deck information}

Figure 4 depicts a simplified example of deck information; some of the information inputted as deck information included the hull boundary, fixed components, maintenance space, and module arrangement area. In this study, three series ships were set as the targets, with each ship comprising a three-deck structure. Therefore, information regarding the nine decks was input as the initial condition. Consequently, the mesh size was set as $40 \times 40 \mathrm{~cm}$.

\subsubsection{Module information}

Module information comprises information related to the size and limitations of the arrangement. As illustrated in Table 1, modules $\mathrm{A}$ and $\mathrm{B}$ are 6 columns $\times 4$ rows and 5 columns $\times 5$ rows, respectively. Both modules (A and B) were to be arranged on the 3rd deck. Module A was to be arranged on the port side and module $\mathrm{B}$ on the starboard side.

Table 1 Example of module information

\begin{tabular}{ccccccc}
\hline ID & C & R & Partial & $3^{\text {rd }}$ Deck & $2^{\text {nd }}$ Deck & S or P \\
\hline A & 6 & 4 & & 1 & & P \\
B & 5 & 5 & & 1 & & S \\
\hline
\end{tabular}

\subsubsection{Pipe information}

Pipe information indicates the number of pipe connections between the modules, along with the weight-per-unit-length data for each pipe. These data are used to calculate the pipe length and weight.

\subsubsection{Design variables and gene representation}

The basic unit of a chromosome is the arrangement information of one module for three series ships. Figure 5 shows the gene sequence for a module of the 58BC, $82 \mathrm{BC}$, and $98 \mathrm{BC}$ series. This illustration demonstrates single module placement for three series ships. The gene sequence is further divided into four parts; the first part is reserved for the deck decision while the other parts determine the module positions in the three series ships. In Figure 6, the module position of 58BC is " 7, , $82 \mathrm{BC}$ is " 6 ," and $98 \mathrm{BC}$ is " 10. ."

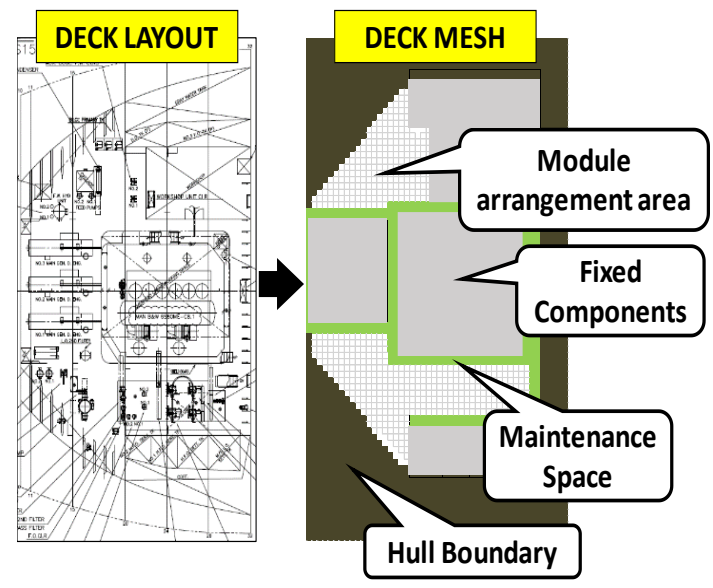

Figure 4 Deck information 


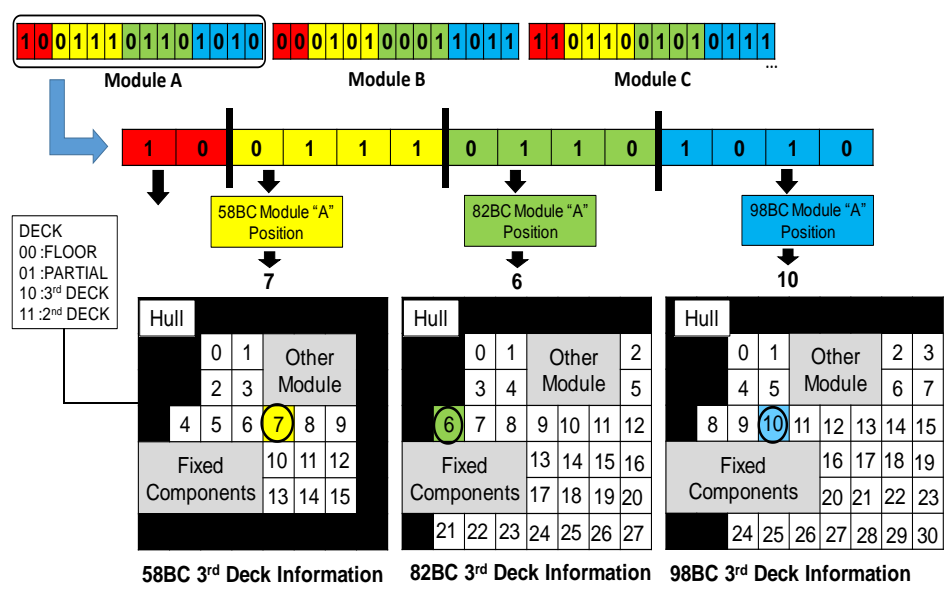

Figure 5 Gene representation for module placement

\subsubsection{Objective function}

As previously mentioned, the piping cost and similarity in arrangement for ships belonging to various series types were set as the objective functions in this study.

\subsubsection{Cost calculation}

The lengths of individual pipes were first calculated based on the following rules.

- The two extreme ends of each pipe were considered to be centers of connected modules.

- In the case of pipes placed on the same deck, the number of meshes between the two extremities of the pipe was determined. Only those meshes in the vertical and horizontal directions were considered.

- When the pipes were placed on different decks, the height of the deck was also added when measuring the pipe lengths.

\subsubsection{Similarity calculation}

The position of the modules for each series was normalized using Equation 1, while the similarity was calculated using Equation 2.

$$
\begin{gathered}
(\mathrm{x}, \mathrm{y})=\left(\frac{\mathrm{x}_{\mathrm{o}}}{\text { sum of columns }}, \frac{\mathrm{y}_{\mathrm{o}}}{\text { sum of rows }}\right) \\
\text { Similarity }=\sum\left\{\sqrt{\left(\mathrm{x}_{1}-\mathrm{x}_{2}\right)^{2}+\left(\mathrm{y}_{1}-\mathrm{y}_{2}\right)^{2}}+\sqrt{\left(\mathrm{x}_{2}-\mathrm{x}_{3}\right)^{2}+\left(\mathrm{y}_{2}-\mathrm{y}_{3}\right)^{2}}+\sqrt{\left(\mathrm{x}_{3}-\mathrm{x}_{1}\right)^{2}+\left(\mathrm{y}_{3}-\mathrm{y}_{1}\right)^{2}}\right\}
\end{gathered}
$$

\section{$x$ : column position after normalization $y$ : row position after normalization $x_{o}$ : original column position $y_{0}$ : original row position}

$\left(x_{1}, y_{1}\right):$ module normalized coordinate of $58 B C$ $\left(x_{2}, y_{2}\right):$ module normalized coordinate of $82 B C$ $\left(x_{3}, y_{3}\right)$ : module normalized coordinate of $98 B C$

The above equations represent a summary of the relative distance of one module within the normalized deck area.

\section{RESULTS AND DISCUSSION}

\subsection{Problem Definition}

To evaluate the effectiveness of our study, the following optimizations were performed.

Case 1: Current arrangement in the company.

Case 2: Optimization of a single ship.

Case 3: Optimization of one series of ships.

Case 4: Optimization of ships of different sizes belonging to various series. 


\subsection{Optimization Results and Discussion}

\subsubsection{Optimization results}

To solve the above optimization problem, a genetic algorithm was adopted. The results of the optimization operation are depicted in Figure 6. As shown in the figure, the modular arrangements of all three series of ships were generated in a single optimization run.
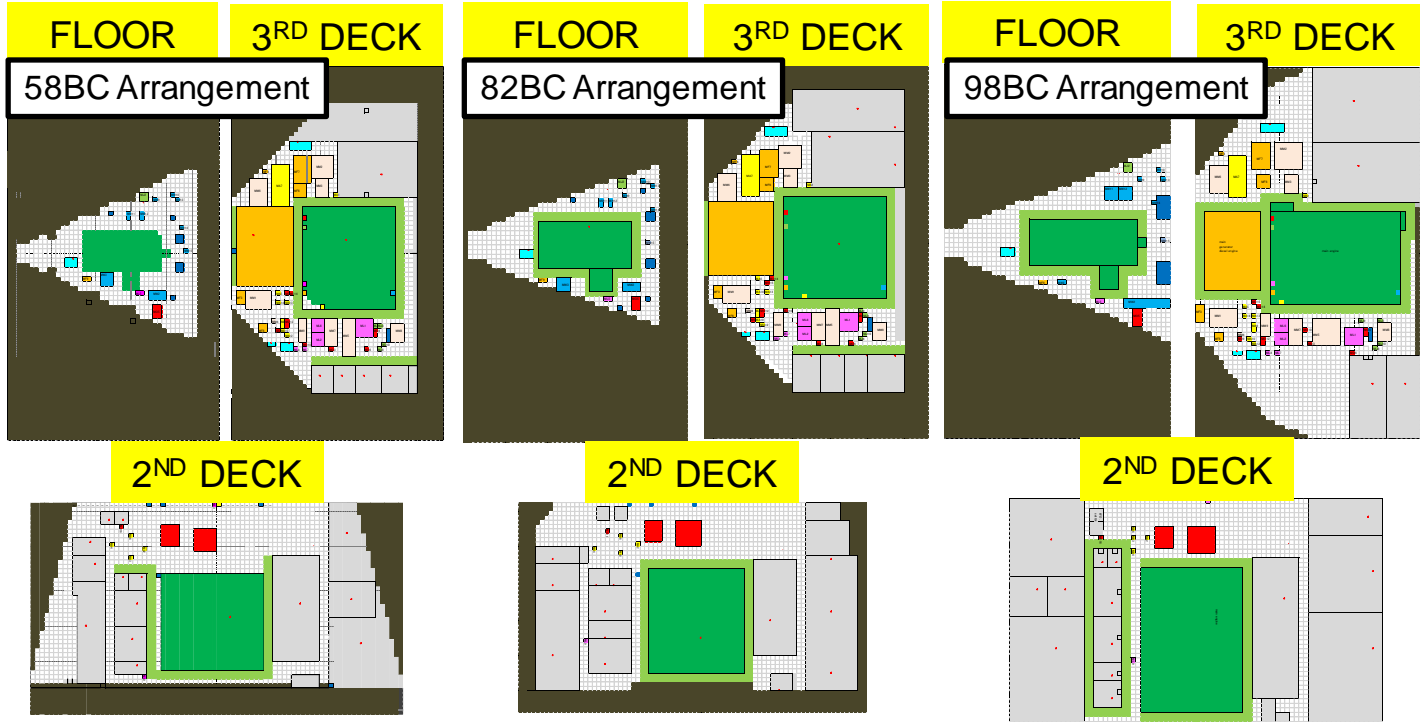

Figure 6 Optimization results

\subsubsection{Cost comparison}

Table 2 compares the costs and pipe lengths for Cases $1-4$. The cost and pipe length for Case 1 were set as 100. As observed in the table, Case 2 is the most optimal in terms of cost and pipe length. However, there are slight differences between the corresponding values for Cases 3 and 4 compared with Case 2. The cost difference between Case 1 and Case 4 is approximately $0.15 \%$ for $58 \mathrm{BC}, 3.62 \%$ for $82 \mathrm{BC}$, and approximately $3.38 \%$ for $98 \mathrm{BC}$.

Table 2 Optimization results

\begin{tabular}{llcccc}
\hline \multicolumn{2}{c}{ Result } & Case 1 & Case 2 & Case 3 & Case 4 \\
\hline \multirow{2}{*}{ 58 BC } & Length & 100 & 97.93 & 98.09 & 98.23 \\
& Cost & 100 & 98.27 & 98.29 & 98.42 \\
82 BC & Length & 100 & 95.74 & 95.77 & 95.83 \\
& Cost & 100 & 96.32 & 96.33 & 96.38 \\
\multirow{2}{*}{ 98 BC } & Length & 100 & 95.08 & 95.19 & 95.33 \\
& Cost & 100 & 96.49 & 96.53 & 96.62 \\
\hline
\end{tabular}

\subsubsection{Comparison of arrangements}

Figure 7 demonstrates the positions of the modules $\left(3^{\text {rd }}\right.$ deck on the port side) corresponding to Cases 1-4 for the three series of ships. As shown in the figure, the modular positions for the three series of ships are different for Cases 1-3. However, in Case 4, the modular positions for the three series of ships are similar, although the sizes of their corresponding modules and decks are largely different. A similar arrangement has been observed to be beneficial in terms of maintenance and design/production lead time. Therefore, Tsuneishi Shipbuilding Co., Ltd employed the proposed arrangement in its ship designing. 


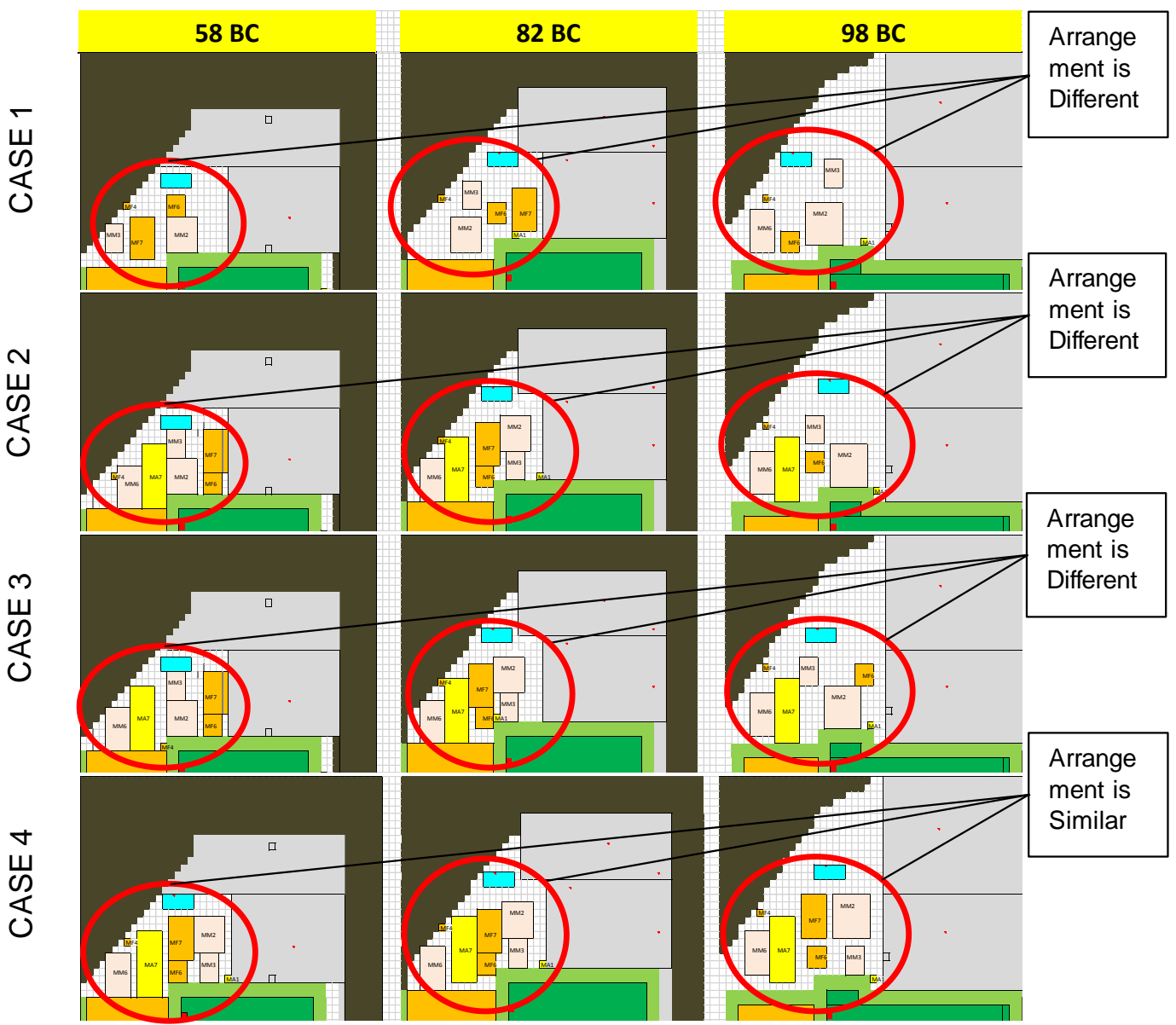

Figure 7 Differences in the optimized arrangements on the $3^{\text {rd }}$ decks of ships belonging to three different series and the current arrangement in the company

\subsubsection{Discussion}

This section describes the relationship between the methodology and results. The methodology of this paper is composed of two important aspects; modularization and arrangement. In terms of modularization, the results satisfy all of the requirements stated in section 2.1.2.1. While for the arrangement, there are two aspects that need to be considered, i.e., cost and similarity. As mentioned in Table 2, Case 2 is the most optimal result regarding the cost calculation. However, the target of this study is not a single ship but rather various types of series ships. Based on Table 2, the cost of Case 4 is slightly higher than that of Case 2.

However, the arrangements for Case 1, Case 2, and Case 3 differ according to the series of ships. On the other hand, however, the arrangements of Case 4 are similar across all series of ships. Case 4 has a similar arrangement because the data for all of the series of ships were optimized at the same time and included a similarity calculation as a part of the objective function. Therefore, the following characteristics of the proposed methodology are important to obtain the optimum arrangement of a series of ships.

- The piping data for all series of ships are collected and the modularization using DSM is carried out at once considering the common parts and optional parts.

- The optimization of arrangements for the various types of series ships are executed simultaneously.

- In addition to the cost, the similarity of the arrangements is considered and is set as the objective function. 


\section{CONCLUSION}

This study presents a new piping system arrangement with respect to series of ships in line with the modularization concept. Thus, the design and layout of the piping arrangement were first divided into two stages - module definition and module arrangement. The DSM method was adopted in order to define an effective module that offers commonality of usage across different ships. Furthermore, an optimization system was developed to determine the module arrangement using a genetic algorithm in order to obtain exceptionally similar module-arrangement patterns for ships belonging to various series types, with specific consideration given to piping cost and similarity.

The following conclusions can be inferred from this study: (1) Modularization is an effective method for reducing the complexity of piping design in the engine rooms of ships; (2) In considering various types of series ships, a common modularization was obtained for both common parts and optional parts; (3) A genetic algorithm was used to optimize the module arrangement design; (4) Use of the proposed method results in the attainment of a similar arrangement design for ships belonging to various series types.

\section{REFERENCES}

Baade, R., Klinge, F., Lynaugh, K., Woronkowicz, F., Siedler, K.M., 1998. Modular Outfitting. Journal of Ship Production, Volume 14(3), pp. 170-179

Chen, P.P.-S., 1976. The Entity-relationship Model toward an un-fined View of Data. ACM Transactions on Database Systems, Volume 1(1), pp. 9-36

Chen, Y., Feng, C., Wang, Y., Wu, H., 2011. Using BIM Model and Genetic Algorithms to Optimize the Crew Assignment for Construction Project Planning. International Journal of Technology. Volume 2(3), pp.179-187

Eppinger, S.D., Browning, T.R., 2012. Design Structure Matrix Methods and Applications. MIT Press, USA

Helvacioglu, S., Insel, M., 2005. A Reasoning Method for a Ship Design Expert System. Expert Systems: International Journal of Knowledge Engineering and Neural Networks, Volume 22(2), pp. 72-77

Jaquith, P.E., Burns, R.M., Dunbarr, S.E., Fontaine, B.J., Nelson, H.A., Silveira, John L., 1996. Modular Engine Room Design and Construction for the Strategic Sealift Ships. Journal of Ship Production, Volume 12(4), pp. 230-243

Kamrani, A.K., Salhieh, S.M., 2002. Product Design for Modularity. Kluwer Academic Publisher, USA

Kim, S.-Y., Moon, B.-Y., Shin, S.-C., 2009. Evaluation Criterion of Machinery Arrangement Design in a Ship Engine Room. Journal of Ship Production, Volume 25(3), pp. 117-125

Kimura, H., 2011. Automatic Designing System for Piping and Instruments Arrangement including Branches of Pipes. In: International Conference on Computer Applications in Shipbuilding (ICCAS), pp.93-99

Koga, T., Niwa, T., Aoyama, K., 2009. A Modular Design Method for an Engine Room based on an Integrated Network Description and Division. In: $10^{\text {th }}$ International Marine Design Conference, pp. 1-9

Lee, D.-M., Kim, S.-Y., Moon, B.-Y., Kang, G.-J., 2013. Layout Design Optimization of Pipe System in Ship Engine Room for Space Efficiency. Journal of the Korean Society of Marine Engineering, Volume 37(7), pp. 784-791

Lindemann, U., Maurer, M., Braun, T., 2009. Structural Complexity Management. SpringerVerlag Berlin Heidelberg, Germany 
Singh, S.P., Sharma, R.R.K., 2006. A Review of Different Approaches to the Facility Layout Problem. International Journal of Advanced Manufacturing Technology, Volume 30(5), pp. 425-433

Tomassoni, C., Huynh, T., Schiller, T., 2003. Production-based Design Methodology for Shipboard Machinery Spaces. Journal of Ship Production, Volume 19(1), pp. 53-63

Wu, B.C., Young, G.S., Schmidt, W., Choppella, K., 1998. Applying Fuzzy Functions and Sequential Coordination to Optimization of Machinery Arrangement and Pipe Routing. Naval Engineers Journal, pp. 43-54 